\section{Wolfgang Pauli's 100th birthday}

\section{A personal view by Prof.C.P.Enz,W.Pauli's last assistant}

A ccording to a recent inquiry by Physics World concerning the ten most important physicists ever, Wolfgang Pauli does not belong to them. For those of an older generation for whom Pauli was "the conscience of physics" this comes as a surprise. But it shows perhaps that both his exclusion principle and his neutrino idea - which at first were hard to swallow - have since become household words, while his proverbial wit is lost to a generation communicating by e-mail.

So who was this man? Pauli was born just 100 years ago on 25 April 1900 in Vienna. His father Wolf Pascheles came from a well-known Jewish family in Prague where he studied medicine with one of Ernst Mach's sons and took physics classes from Mach himself. As a young medical doctor Wolf Pascheles settled in Vienna in 1893, took the name of Pauli, was baptized Catholic and married in 1899. Mach, who accepted a chair of philosophy at the University of Vienna in 1895 accepted to be godfather for Pauli's son Wolfgang.

At age 13 Wolfgang read Mach's famous Mechanics that the latter had given him with a dedication. At 18, before becoming a student of Arnold Sommerfeld in $\mathrm{Mu}$ nich, Pauli published his first paper on general relativity. Sommerfeld, who saw that this young man could not learn much more from him, let Pauli write a review on relativity in the Encyklopädie der Mathematischen Wissenchaften. This almost perfect work published in 1921 (still a standard reference today) made Pauli famous. Pauli's biting wit was already wellknown. When in 1922 Paul Ehrenfest who had also written an Encyklopädie article - met Pauli, he said to him : "Pauli, I like your Encyklopädie article better than yourself", to which Pauli answered : "How strange, with me it is just the opposite!". In Copenhagen where Pauli spent the year $1922 / 23$ at Bohr's institute he became a good friend of Bohr's assistant Hans Kramers who remarked : "Pauli, your heart is better than your wit!".

The following six years Pauli spent in Hamburg where three fundamental ideas were born. First, Pauli introduced the fourth quantum number of the electron that later was recognized as the spin. Then, making use of this fourth quantum number, he formulated the exculsion principle which could explain the periodic system of the elements and later was recognized to be responsible, quite generally, for the stability of matter. But even before that he had postulated the existence of a nuclear spin in order to explain the hyperfine anomalies in the spectra. Hamburg also was the scene of Pauli's discussions with Otto Stern. But in spite of this friendship Stern would not let Pauli enter his laboratory - because of the Pauli effect. For, it was said that every time Pauli entered a laboratory something went wrong. Pauli believed in it and was amused.

In 1928 Pauli became the successor of Peter Debye at ETH, the Swiss Federal Institute of Technology in Zurich. He asked for only one condition, namely to have a research assistant. Pauli stayed in this position to the end of his life, and at the same time the assistantship was occupied 12 times. The first of Pauli's assistants was Ralf Kronig. With him and with his experimental colleague Paul Scherrer, Pauli explored the night life of Zurich. The second assistant, Felix Bloch, later received the Nobel Prize. Of the third, Rudolf Peierls from Berlin, Pauli said : "Peierls, he speaks so fast, when one understands what he has said he already claims the contrary". Hendrik Casimir, the fourth assistant, later became a director with Philips at Eindhoven. When Pauli then heard that one was going to Holland he would say : "when you see Casimir, call him 'Herr Director', for, that vexes him!". His fifth assistant, Victor Weisskopf had the misfortune to publish the result for the self-energy of the electron with the wrong sign, whereupon Pauli mused : "I should have taken Bethe!" For, Hans Bethe was an accomplished calculator, but he worked on the solid state which displeased Pauli. Apparently, later assistants came away with milder jugements until the last, myself, who at the beginning ignored that organizing tickets for classical concerts for Pauli and collaborators was one of the assistant's tasks. One day I had in my mail a card from a bar in downtown Zurich, on which Pauli complained that he had missed a concert with Isaac Stern and which closed "with the hope of better times".

There was also a more hidden side to Pauli's personality. At the beginning of his professorship at ETH he developed a neurosis which manifested itself in the fact that, as he told his friend and colleague at the University of Zurich, Gregor Wentzel, "with the women things don't go at all". In fact, a first marriage failed after less than a year. It was during this period, however, that Pauli had the idea of the neutrino as the only way out of the problem of an energy deficit in the beta-decay. - In 1932 Pauli met the famous psychiatrist Carl Gustav Jung in Zurich which resulted in a psychoanalysis during three years. Shortly afterwards Pauli remarried, this time durably. Jung had immediatly seen that Pauli had frequent dreams containing a wealth of archaic material that caught Jung's keen interest. From this time on Pauli wrote up his dreams, and a fascinating exchange of ideas developed between Pauli and Jung which lasted almost to the end of Pauli's life.

The war years, from 1940 to 1946 Pauli spent in the United States at the Institute for Advanced Study in Princeton. There he published the famous spin-statistics theorem which probably constitutes his most brilliant paper. It was in Princeton that in November 1945 the news of his Nobel Prize for the exclusion principle reached him. But Pauli went to Stockholm only in 1946 , on the way back to ETH in Zurich. Instead there was a great celebration in Princeton where Einstein unexpectedly rose for a toast, in which he designated Pauli his spiritual son and successor at the Insitute for Advanced Study.

Back in Zurich Pauli's institute became a world centre of quantum field theory. Moreover Pauli, influenced by his dreams, also devoted much time to the archetypal background of physical ideas. This he first exemplified with Johannes Kepler, on whom he wrote an important essay, and went on to physical notions in general. In the mid-fifties, again guided by dreams, he turned his attention to symmetries and wrote the important paper on the CPTtheorem This was like a presentiment of the sensational news in January 1957 of parity violation in weak decays. The last year of his life Pauli let himself be carried away by the "world formula", a non-linear Dirac equation, of his life-long friend Werner Heisenberg who had succeded in building into it an internal symmetry. But realizing the shortcomings of this approach, Pauli soon withdrew again in disappointment. And after a short struggle with cancer he died in Zurich on 15 December 1958 . 